\title{
INSTALASI DAN EVALUASI GROUNDING UNTUK MBE INDUSTRI LATEKS PTAPB MENGGUNAKAN MULTIPLE ROD
}

\author{
Suyamto, Sutadi, Elin Nuraini \\ *)Pusat Teknologi Akselerator dan Proses Bahan, BATAN, \\ Jl. Babarsari P.O.Box 6101 ykbb, Yogyakarta 55281 \\ e-mail : ptapb@batan.go.id
}

Diterima 13 Mei 2011, diterima dalam bentuk perbaikan 07 Desember 2011, disetujui 16 Januari 2012

\begin{abstract}
ABSTRAK
INSTALASI DAN EVALUASI GROUNDING UNTUK MBE INDUSTRI LATEKS PTAPB MENGGUNAKAN MULTIPLE ROD. Telah dilakukan instalasi dan evaluasi grounding pada MBE untuk industri lateks PTAPB menggunakan multiple rod. Instalasi didasarkan pada kebutuhan nilai tahanan pentanahan $R_{p}$ yang kecil dengan cara pemilihan bentuk, ukuran dan jumlah elektrode serta lokasi penanaman elektrode. Agar diperoleh resistivitas tanah $\rho$ yang rendah, sumur ditimbun tanah liat pada bagian di sekitar elektrode. Instalasi dilakukan dengan menanam elektrode-2 batang tembaga (Cu) pejal diameter 16 mm pada 2 buah sumur, masing-2 berjumlah 4 buah @ 2 meter dan 8 buah @ 1 meter, menembus 2 lapisan tanah. Dengan konfigurasi elektrode yang telah ditentukan, diperoleh $R_{p}$ terukur rata-rata 3,99 $\Omega$ pada sumur I dan 5,82 $\Omega$ pada sumur II atau $R_{p t}=2,36 \Omega$ jika dirangkai paralel, sedangkan dari pengukuran setelah keduanya dikopel diperoleh nilai rata-rata $R_{p t}=1,97 \Omega$. Dari perhitungan secara trial and error dengan memvariasi $\rho$, diperoleh tahanan tanah bagian atas $R_{1}=6,53 \Omega$ dan tahanan tanah bagian bawah $R_{2}=10,41$ $\Omega$ atau jika diparalel $R_{p l}=4,01 \Omega$ untuk sumur I, sedangkan untuk sumur II diperoleh $R_{1}=7,72 \Omega$ dan $R_{2}=23,64 \Omega$ yang jika diparalel diperoleh $R_{p 2}=5,81 \Omega$. Bila tahanan pada sumur I dan II diparalel diperoleh $R_{p t}=2,37 \Omega$. Perbedaan $R_{p t}$ antara pengukuran dan perhitungan 0,40 $\Omega$ sangat dimungkinkan karena pengukuran $R_{p t}$ sulit dilakukan dan sangat dipengaruhi oleh inhomogenitas resistivitas tanah antara satu tempat dengan tempat yang lain. Dari evaluasi diketahui bahwa pengaruh panjang dan kedalaman penanaman lebih dominan dibanding dengan jumlah elektrode. Dengan perbedaan kedalaman elektrode 0,55 m dibanding dengan jumlah elektrode 2 kali diperoleh perbedaan tahanan yang sangat besar yaitu $18,47 \Omega$.
\end{abstract}

Kata kunci : MBE, tahanan pentanah, batang banyak

\begin{abstract}
INSTALLATION AND EVALUATION OF GROUNDING SYSTEM FOR EBM INDUSTRIAL LATEX AT PT APB USING MULTIPLE ROD. Installation and evaluation of grounding system for EBM industrial latex at PT APB using multiple rod has been carried out. Installation is based on the needs of small grounding resistance $\left(R_{p}\right)$ value by choosing the shape, size and number of electrode and the electrodes planting location. The well backfilled with clay in order to obtain low soil resistivity $\rho$ on surrounding the electrode. Installation is done by planting the electrodes copper rod $(\mathrm{Cu})$ diameter of $16 \mathrm{~mm}$ in 2 wells, each consists of 4 pieces @ 2 meters length and 8 pieces @ 1 meter length through 2 layers soil. From the electrodes with a predetermined configuration, obtained the average measured value of $R_{p}$ is $3.99 \Omega$ in wells I and $5.82 \Omega$ in wells II or $R_{p t}=2,36 \Omega$ in parallel, whereas the average of measurements value of electrodes is $R_{p t}=1.97 \Omega$. From trial and error by varying of $\rho$ it is obtained that the resistance on the upper soil $R_{1}=$ $6.53 \Omega$ and $R_{2}=10.41 \Omega$ for the bottom soil or in parallel obtined $R_{p l}=4.01 \Omega$ for wells $I$, while for wells II $R_{1}=7.72 \Omega$ and $R_{2}=23.64 \Omega$ that if in parallel obtined $R_{p 2}=5.81 \Omega$. When resistance on I and II wells being paralleled $R_{p t}$ value is $2.37 \Omega$. The difference values of measured and calculation $R_{p t}$ value is $0.40 \Omega$, it might be caused by the difficulty on $R_{p t}$ measurement and the effect of inhomogenity of ground resistivity from one place to another place. From the evaluation found that the influence of length and depth of planting electerodes more dominant compared to the number of electrodes. With the difference of $0.55 \mathrm{~m}$ electrode depth and 2 times the number of electrode obtained a very large difference in resistance i.e $18.47 \Omega$
\end{abstract}

Key words : EBM, grounding resistance, multiple rod

\section{PENDAHULUAN}

$\mathrm{M}$ esin Berkas Elektron (MBE) untuk industri lateks merupakan salah salah peralatan baru yang sedang dikembangkan oleh PTAPB yang di dalamnya terdapat sumber tegangan tinggi. Apabila terjadi hubung 
singkat atau arus bocor dari konduktor yang bertegangan ke bodi, akan dapat mengakibatkan hal-hal yang tidak diinginkan seperti (1):

1. Membahayakan operator bila menyentuh atau berada di sekitar peralatan tersebut,

2. Terjadi kebakaran bila arus bocor tersebut mengalir dari sumber yang bertegangan menunju netral atau bodi melalui medium yang mudah terbakar.

Untuk itu pada MBE perlu diinstal suatu pentanahan dengan tujuan utama adalah untuk perlindungan terhadap personil dan pencegahan dari kemungkinan terjadinya kebakaran. Evaluasi perlu dilakukan terhadap hasil instalasi dengan maksud untuk menganalisis besarnya tahanan pentanah yang telah diperoleh. Metode yang digunakan adalah dengan cara pengukuran berulang-ulang dan memvariasi posisi penanaman probe alat ukur sehingga diperoleh data yang banyak, kemudian dibandingkan dengan teori dan hasil perhitungan perencanaan yang telah dilakukan sebelumnya.

\section{TEORI}

Grounding atau pentanahan dalam sistem kelistrikan merupakan hal yang sangat penting karena sesuai dengan fungsinya dapat berlaku sebagai alat untuk tujuan pencegahan, keselamatan maupun untuk tujuan perlidungan, sebagai berikut: (Gambar 1) yaitu $(2,3,4)$ :

1. Pencegahan terhadap sinyal dari gangguan gelombang elektromagnetik yang berasal dari luar (signal ground, antene ground),

2. Keselamatan terhadap manusia atau operator, pencegahan terhadap kerusakan peralatan dan kemungkinan terjadinya kebakaran apabila terjadi hubung singkat antara konduktor yang bertegangan dengan bodi peralatan (cabinet ground, safety ground),

3. Perlindungan terhadap bangunan dan saluran tenaga transmisi maupun distribusi listrik dari sambaran petir (building ground, power ground).

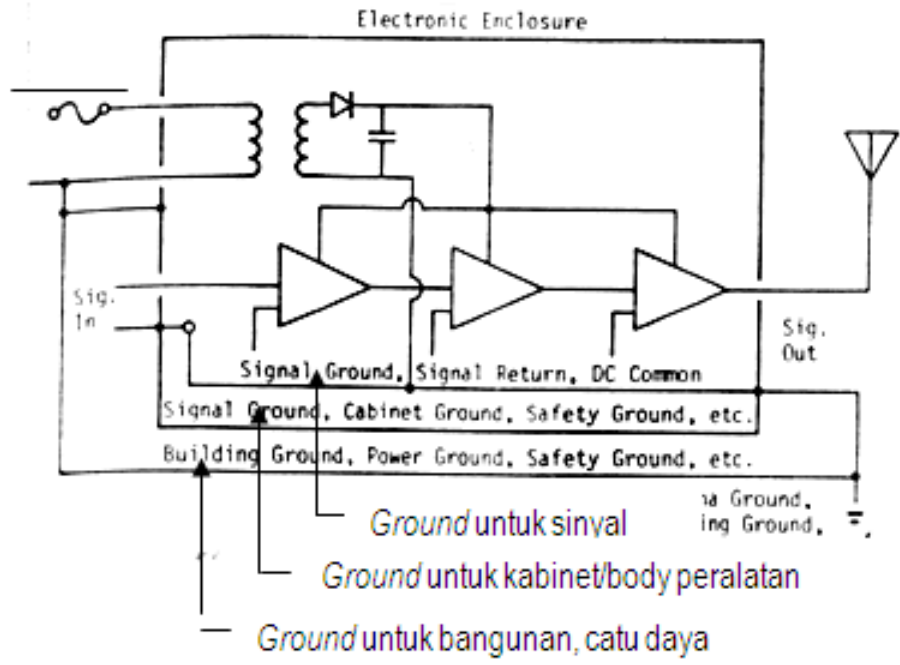

Gambar 1. Beberapa fungsi dari sistem pentanahan

\section{Syarat-syarat Instalasi Pentanahan yang Efektif}

Prinsip dan teori dari setiap pentanahan adalah sama yaitu sistem pentanahan yang dibuat dan diusahakan mempunyai tahanan pentanah $\left(R_{p}\right)$ yang sekecil mungkin. Tujuannya adalah agar bila terjadi arus gangguan, dapat mengalir ke dalam tanah secara cepat dan dalam jumlah yang besar sehingga arus gangguan yang melewati tubuh manusia sangat kecil sehingga aman ${ }^{(1,5,6)}$.

Dalam instalasi sistem pentanahan ada beberapa faktor yang perlu dipertimbangkan antara lain adalah tahanan jenis tanah, struktur tanah, keadaan lingkungan, biaya, ukuran dan bentuk elektrode yang akan dipasang. Secara umum untuk menghasilkan $R_{p}$ yang lebih kecil diperlukan biaya yang lebih besar dan sebaliknya, sehingga sebelum dibuat instalasi sistem pentanahan perlu dipertimbangkan fungsi dan efek ekonomisnya serta disesuaikan dengan keperluannya. Syarat-syarat yang harus dipenuhi agar suatu pentanahan efektif adalah(5,6,7): 
1. Rp harus memenuhi syarat yang diinginkan untuk suatu keperluan pemakaian tertentu,

2. Elektrode yang ditanam harus dari bahan konduktor yang baik, tahan korosi dan cukup kuat,

3. Elektrode harus mempunyai kontak yang baik dengan tanah di sekelilingnya,

4. Rp harus baik untuk berbagai musim selama setahun,

5. Biaya pemasangan serendah mungkin.

Dari semua rumusan untuk berbagai macam bentuk elektrode diketahui bahwa $R_{p}$ berbanding lurus dengan besarnya resistivitas atau tahanan jenis tanah $\rho$ (lihat Lampiran 1), sehingga dalam hal ini banyak dilakukan usaha untuk memperkecil $\rho$.

Untuk berbagai tempat, nilai $\rho$ tidak sama dan tergantung pada beberapa faktor antara lain:

1. Sifat geologi tanah,

2. Komposisi zat kimia dalam tanah,

3. Kandungan air tanah,

4. Suhu tanah,

5. Perubahan musim.

Sifat geologi tanah merupakan faktor utama yang menentukan tahanan jenis tanah. Bahan dasar tanah relatif bersifat bukan penghantar dan umumnya mempunyai $\rho$ rendah, sedangkan batu-batuan dan quartz bersifat sebagai isolator, dapat dilihat pada tahanan jenis tanah dalam Lampiran 2.

Kandungan zat-zat kimia dalam tanah perlu diperhatikan terutama bila mengandung garam karena dapat bersifat korosif. Di daerah yang mempunyai tingkat curah hujan tinggi biasanya mempunyai tahanan jenis tanah yang tinggi disebabkan larutnya garam yang terkandung pada lapisan atas. Pada daerah yang demikian ini untuk memperoleh pentanahan yang efektif dilakukan dengan menanam elektrode yang lebih dalam. ${ }^{(7,8)}$

Kandungan air tanah sangat berpengaruh terhadap perubahan $\rho$, terutama kandungan air tanah sampai dengan $20 \%$ dan kenaikan kandungan air tanah di atas 20\% pengaruhnya sedikit sekali.

Suhu tanah di bumi pada kedalaman 1,5 m biasanya konstan atau tidak berubah terhadap perubahan suhu permukaan tanah. Untuk daerah tropis seperti Indonesia perbedaan suhu permukaan tanah selama setahun tidak banyak sehingga faktor perubahan suhu boleh dikatan tidak ada pengaruhnya terhadap $\rho$. Perbedaan tahanan jenis tanah akibat iklim biasanya terbatas sampai kedalaman beberapa meter dari permukaan tanah, selanjutnya pada bagian yang lebih dalam secara praktis akan konstan.

Dengan hal-hal tersebut di atas maka dapat disimpulkan bahwa variasi tahanan jenis tanah sangat besar terutama apabila kondisinya tidak homogen, bahkan pada suatu lokasi tertentu sering dijumpai beberapa jenis tanah yang mempunyai $\rho$ yang berbeda-beda (non uniform)(9,10). Oleh sebab itu pada pemasangan sistem pentanahan dalam suatu lokasi, peralatan pentanahan ditanam pada dua atau lebih lapisan tanah yang berbeda yang berarti bahwa $\rho$ di tempat tersebut tidak sama.

\section{Faktor-faktor yang Menentukan Tahanan Pentanah}

Telah dijelaskan sebelumnya bahwa untuk mecapai tujuan pentanahan, tahanannya harus dibuat sekecil mungkin dan tahanan pentanahan tersebut tergantung pada tiga faktor yaitu $(5,7)$ :

1. Tahanan elektrode itu sendiri dan penghantar yang menghubungkan ke peralatan yang ditanahkan.

2. Tahanan kontak antara elektrode dengan tanah.

3. Tahanan massa tanah sekeliling elektrode.

Pada prakteknya tahanan elektrode dapat diabaikan, sedangkan tahanan kawat penghantar yang menghubungkan ke peralatan mempunyai impedansi yang tinggi terhadap impuls frekuensi tinggi misalnya pada saat terjadi lightning discharge. Untuk menghindarinya, sambungan ini diusahakan dibuat sependek mungkin $(9,10$, 11). Dari ketiga faktor tersebut di atas yang paling dominan pengaruhnya adalah tahanan sekeliling elektrode yang merupakan fungsi dari $\rho$. Disamping itu untuk memperoleh $R_{p}$ yang kecil tidak mudah karena parameternya sangat banyak antara lain bahan, ukuran dan jenis elektrode, kedalaman penanaman elektrode, teknik penyambungan dan lain-lain.

Bentuk-bentuk elektrode yang ditanam berikut perumusannya ditunjukkan pada Lampiran 1, berlaku untuk tanah yang homogen sehingga resistivitasnya sama untuk setiap kedalaman penanaman ${ }^{(6,10,12)}$. Namun dari beberapa perhitungan dan berdasarkan pengalaman yang telah dilakukan sebelumnya diketahui bahwa dengan elektrode bentuk batang akan dihasilkan $R_{p}$ yang paling rendah. Selain itu bila penanamannya lebih dalam atau 
semakin jauh dari permukaan tanah, pada tanah yang tidak homogen dan dalam jumlah banyak (multiple rod) juga akan diperoleh $R_{p}$ yang lebih kecil lagi(5,7,10,13,14), sehingga untuk memperoleh $R_{p}$ yang kecil banyak dilakukan penanaman elektrode seperti yang ditunjukkan pada Gambar 2.

Bahan elektrode batang harus dipilih sedemikian hingga:

1. Memiliki daya hantar jenis (conductivity) yang besar sehingga tidak memperbesar beda potensial lokal yang berbahaya,

2. Memiliki kekuatan mekanis yang tinggi terutama bila digunakan pada daerah yang tidak terlindung terhadap kerusakan fisik.

3. Mudah disambung secara elektrik sehingga tidak mudah putus walaupun dialiri arus gangguan yang besar dan dalam waktu yang lama.

4. Tahan terhadap korosi.

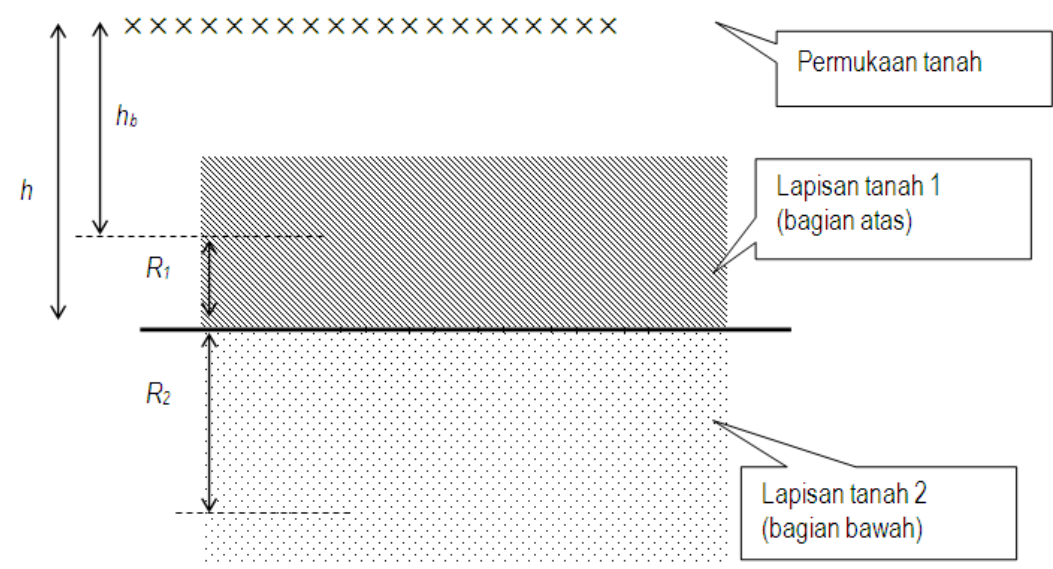

Gambar 2. Beberapa batang elektrode tegak lurus ke dalam tanah

Dengan susunan batang-batang elektrode yang ditanam tegak lurus ke dalam tanah dalam jumlah yang banyak (multiple rod), menembus lapisan tanah kedua, jarak penanaman antara batang elektrode sama seperti pada Gambar 2 tersebut di atas, besarnya $R_{p}$ adalah sebagai berikut(10,13,14).

$$
\begin{aligned}
& R_{p}=\frac{R_{1} R_{2}}{R_{1}+R_{2}} \\
& R_{1}=\frac{\rho_{1}}{\left(h-h_{b}\right)} g_{0} \frac{F_{0}}{N}+\frac{\rho_{1}}{h} \phi_{0} \\
& R_{2}=\frac{\rho_{2}}{\left(L+h_{b}-h\right)} g_{0} \frac{F_{0}}{N} \\
& g_{0}=\frac{1}{2 \pi}\left[\ln \left(\frac{2 L}{a}\right)-1+\frac{\ln 2}{1+\frac{(4 \ln 2) h_{b}}{L}}\right] \\
& F_{0}=\frac{L}{1-0,9 K}, \\
& K=\frac{\rho_{2}-\rho_{1}}{\rho_{2}+\rho_{1}} \\
& \phi_{o}=\frac{\frac{1}{2 \pi}\left(\ln \frac{1}{1-K}\right)}{\sqrt{\left(\frac{N}{F_{o}}-1\right)^{2}+1}}
\end{aligned}
$$

dengan, 
$R_{p}$ : tahanan pentanah total untuk multiple rod $(\Omega)$,

$L$ : panjang elektrode batang $(\mathrm{m})$,

a : jari-jari batang elektrode $(\mathrm{cm})$,

$h_{b}:$ kedalaman penanaman elektrode $(\mathrm{m})$,

$h$ : kedalaman lapisan tanah bagian bawah $(\mathrm{m})$,

$N$ : jumlah batang elektrode,

$K$ : koefisien refleksi,

$\rho_{1}$ : tahanan jenis tanah lapisan bagian atas $(\Omega-m)$,

$\rho_{2}$ : tahanan jenis tanah lapisan bagian bawah $(\Omega-\mathrm{m})$.

\section{METODOLOGI}

Agar dihasilkan $R_{p}$ yang kecil, instalasi pentanahan untuk MBE lateks pertama-tama dilakukan dengan memilih lokasi yang diperkirakan selalu basah sehingga diharapkan tanahnya mempunyai $\rho$ yang kecil, kemudian ditentukan bahan elektrode dan konfigurasinya sebagai berikut:

1. Bahan elekrode adalah tembaga pejal agar terhindar dari galvanic couple yang dapat menyebabkan korosi ${ }^{(7,13) .}$

2. Jumlah sumur 2 buah, jarak antar sumur $7,8 \mathrm{~m}$, kedalaman mencapai air tanah, diameter $80 \mathrm{~cm}$ agar mudah dalam penggaliannya.

3. Diameter elektrode biasanya $5 / 8$ " - 3/4" dengan panjang 4 feet -8 feet ${ }^{(4)}$, sehingga dalam instalasi ini digunakan elektrode batang diameter $16 \mathrm{~mm}$, panjang $L_{1}=2 \mathrm{~m}$ dan $L_{2}=1 \mathrm{~m}$ (Lampiran 3a).

4. Penyambungan elektrode dilakukan seperti pada Gambar 3, sedangkan instalasinya dilakukan seperti pada Gambar 4, dimana masing-masing elektrode ditanam menembus 2 jenis lapisan tanah

5. Tiap elektrode diikat menjadi satu menggunakan baut suri dan disambung dengan kabel tembaga dari jenis scund BC-50, (Lampiran 1b).

6. Agar diperoleh resistivitas yang kecil, sumur ditimbun tanah liat atau tanah lempung (Lampiran 3f), dengan ketinggian seperti yang ditunjukkan pada Gambar 4, kemudian diberi air untuk memperbaiki tahanan kontak antara tanah dan elektrode.

7. Pengukuran besarnya $R_{p}$ dilakukan secara berulang-ulang agar diperoleh data yang lebih akurat

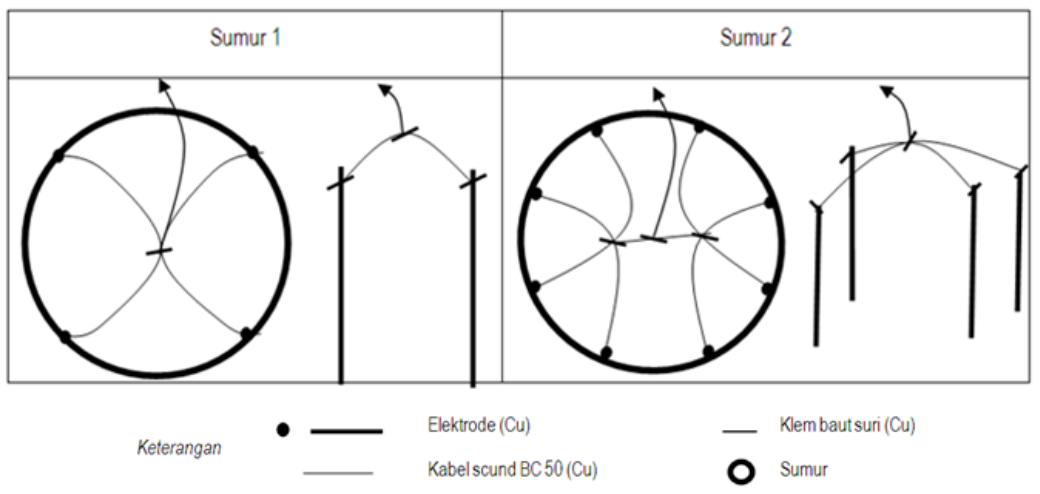

Gambar 3. Penyambungan elektrode (a). tampak atas, (b). tampak samping

\section{HASIL DAN PEMBAHASAN}

Lokasi penanaman elektrode dipilih dan ditentukan di dekat selokan dimana struktur tanahnya (Gambar 4 A): lapisan paling atas sedalam $5 \mathrm{~m}$ berupa tanah urukan, lapisan berikutnya berupa tanah lempung tufaan bercampur pasir berbutir halus sampai kasar berwarna abu-abu (Lampiran $3 e$ ), air tanah dicapai pada kedalaman $7,5 \mathrm{~m}$. Untuk penanaman elektrode, setelah dicapai air tanah kemudian diperdalam $0,2 \mathrm{~m}$ menjadi $7,7 \mathrm{~m}$, pada sumur di sekitar elektrode ditimbun tanah liat (Lampiran 3f) dengan kedalaman 3,6 m, kemudian di atasnya ditimbun tanah galian 
Instalasi dan Evaluasi Grounding untuk MBE Industri Lateks PTAPB menggunakan Multiple Rod (Suyamto, Sutadi, Elin Nuraini)

seperti semula, lihat Gambar 4. Dengan instalasi sistem pentanahan seperti pada Gambar 4 tersebut diharapkan diperoleh $R_{p}$ yang rendah.

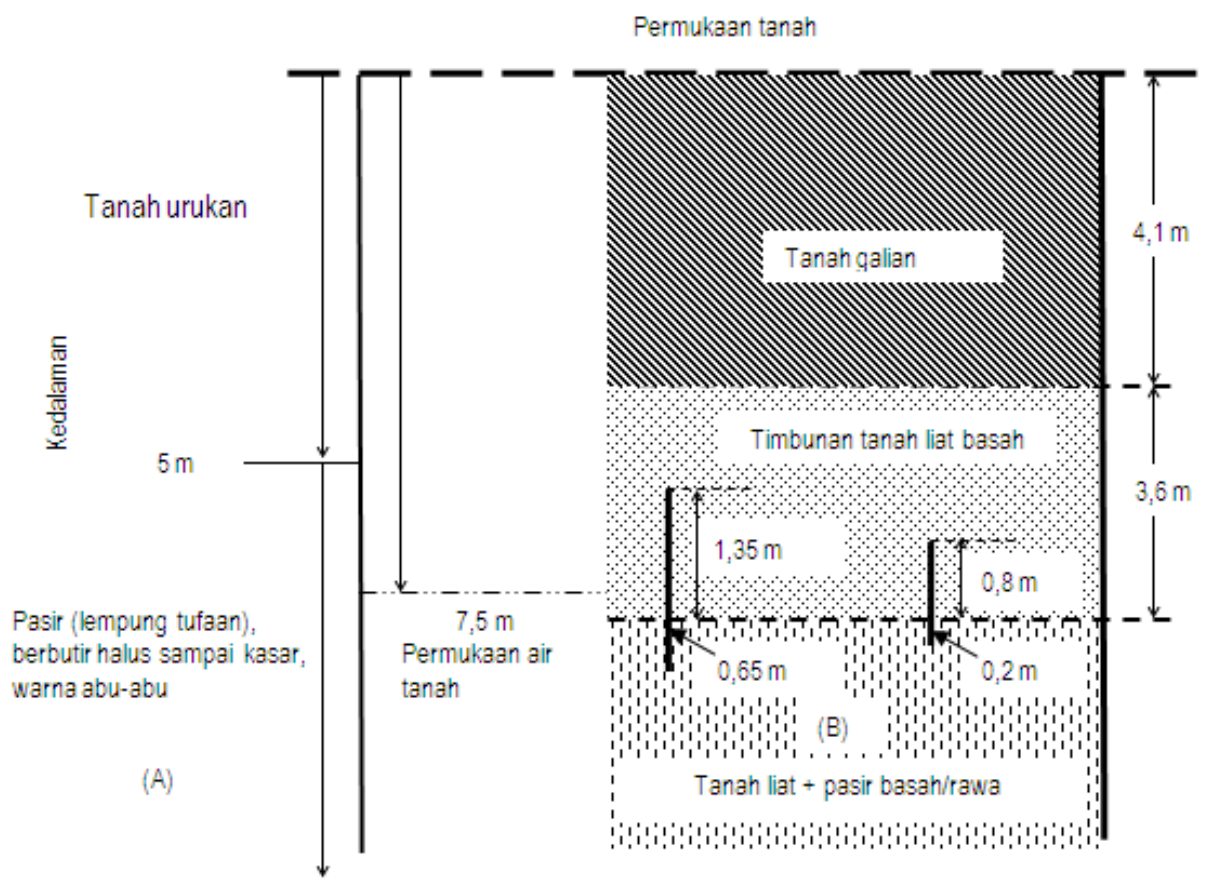

Gambar 4. Struktur tanah di dekat MBE lateks dan penanaman elektrode.

(A). Struktur tanah, (B). Penanaman elektrode pada sumur I dan II

Pengukuran $R p$ dilakukan sebelum dan sesudah elektrode sumur I dan II disusun secara diparalel, menggunakan Earth Resistance Meter (ERM) atau Earth Tester Model 4102 merk KYORITSU dengan posisi kutub ERM yang berbeda (Lampiran 3d) secara berulang-ulang untuk mendapatkan data yang banyak (15). Hasilnya ditunjukkan pada Tabel 1.

Tabel 1. Hasil pengukuran tahanan pentanah $R_{p}(\Omega)$

\begin{tabular}{|c|c|c|c|c|c|c|c|}
\hline \multicolumn{4}{|c|}{ Tahanan tiap sumur } & \multicolumn{4}{c|}{ Tahanan gabungan 2 sumur (paralel) } \\
\hline $\begin{array}{c}\text { Sumur I } \\
N=4, L=2 \mathrm{~m}\end{array}$ & \multicolumn{2}{c|}{$\begin{array}{c}\text { Sumur II } \\
N=8, L=2 \mathrm{~m}\end{array}$} & \multicolumn{2}{c|}{$\begin{array}{c}\text { diukur di sebelah utara } \\
\text { sumur }\end{array}$} & \multicolumn{2}{c|}{$\begin{array}{c}\text { diukur di sebelah selatan } \\
\text { sumur }\end{array}$} \\
\hline $\mathrm{P} 1$ & $\mathrm{P} 2$ & $\mathrm{P} 1$ & $\mathrm{P} 2$ & $\mathrm{P} 1$ & $\mathrm{P} 2$ & $\mathrm{P} 1$ & $\mathrm{P} 2$ \\
\hline 3,8 & 4,1 & 6,3 & 5,4 & 1,4 & 2,0 & 2,0 & 2,4 \\
\hline 3,7 & 4,0 & 6,3 & 5,4 & 1,5 & 1,6 & 2,1 & 2,4 \\
\hline 4,0 & 4,0 & 6,2 & 5,4 & 1,2 & 2,2 & 2,0 & 2,4 \\
\hline 4,0 & 4,0 & 6,2 & 5,4 & 1,6 & 2,0 & 2,1 & 2,4 \\
\hline 4,0 & 4,0 & 6,2 & 5,4 & 1,6 & 2,1 & 2,1 & 2,3 \\
\hline 3,96 & 4,02 & 6,24 & 5,40 & 1,46 & 1,98 & 2,06 & 2,38 \\
\hline 3,99 (rata-rata) & 5,82 (rata-rata) & 1,72 (rata-rata) & 2,22 (rata-rata) \\
\hline \multicolumn{3}{|c|}{2,36 (paralel) } \\
\hline
\end{tabular}

Keterangan : $\mathrm{P}$ adalah posisi pole atau kutub dari ERM. P1 : posisi 3 kutub ERM lurus, sedangkan $\mathrm{P} 2$ posisi kutub tidak lurus. Masing-masing kutub berjarak $>5 \mathrm{~m}$.

Untuk keperluan evaluasi dan analisis tahanan pentanah $R_{p}$, dihitung $R_{1}$ dan $R_{2}$ pada masing-masing sumur berdasarkan persamaan (1) sampai (7). Dalam perhitungan, $\rho_{1}$ dan $\rho_{2}$ diasumsikan dari yang paling jelek berdasarkan Lampiran 2 dan $3 f$ dengan memasukkan syarat-syarat berikut:

1. $\rho_{1}$ dan $\rho_{2}$ harus berharga positif, 
2. Berdasarkan kondisi tanah, $\rho_{1}$ harus lebih besar dari $\rho_{2}$,

3. Berdasarkan sifat paralel, $R_{1}$ dan $R_{2}$ pada sumur I masing-masing harus lebih kecil dari 3,99 $\Omega$, sedangkan pada sumur II harus lebih kecil dari $5,82 \Omega$,

Hasil ilustrasi perhitungan $R_{p}$ dengan nilai parameter-parameter yang telah ditentukan serta dengan mengambil $\rho_{1}$ dan $\rho_{2}$ yang paling jelek yaitu $200 \Omega$-m dan $150 \Omega$-m ditunjukkan pada Tabel $2{ }^{(5)}$.

Tabel 2. Nilai parameter-parameter dan hasil perhitungan $R_{p}(\Omega)$

\begin{tabular}{|c|c|c|}
\hline Parameter & Sumur I & Sumur II \\
\hline$h$ & $7,70 \mathrm{~m}$ & 7,70 \\
\hline$h_{b}$ & $6,35 \mathrm{~m}$ & 6,90 \\
\hline$L$ & $2,00 \mathrm{~m}$ & $1 \mathrm{~m}$ \\
\hline$a$ & $8.10^{-3} \mathrm{~m}$ & $8.10^{-3} \mathrm{~m}$ \\
\hline$N$ & 4 & 8 \\
\hline$\rho$ & $\rho 1=200$ dan $\rho 2=150 \Omega-\mathrm{m}$ \\
\hline$K$ & $-0,142$ & $-0,142$ \\
\hline$g_{0}$ & 0,840 & 0,725 \\
\hline$F_{0}$ & 1,773 & 0,886 \\
\hline$\phi_{0}$ & $-13,0910^{-3}$ & $-2,59.10^{-3}$ \\
\hline$G o F o / N$ & 0,372 & 0,08 \\
\hline$H-h b$ & 1,35 & 0,8 \\
\hline$L+h b-h$ & 0,65 & 0,2 \\
\hline$R$ & $R_{1}=54,77 ; R_{2}=85,84$ & $R_{1}=19,93 ; R_{2}=60$ \\
\hline$R_{p t}=33,43$ & $R_{p}=14,96$ \\
\hline \multicolumn{2}{|c}{10,22} \\
\hline
\end{tabular}

Terlihat pada Tabel 2 bahwa hasil perhitungan $R_{p}$ sangat jauh berbeda jika dibandingkan dengan hasil pengukuran, hal ini terjadi karena dalam perhitungan diambil asumsi $\rho$ yang paling jelek. Padahal $\rho$ merupakan faktor yang paling dominan terhadap $R_{p}$ sehingga pada pengambilan asumsi $\rho$ yang tidak tepat akan dihasilkan $R_{p}$ yang sangat berbeda dengan hasil pengukuran. Di samping itu dari perhitungan juga diketahui bahwa nilai $\left(\frac{\rho_{1}}{h} \phi_{0}\right)$ sangat kecil (lihat Tabel 2) sehingga dapat diabaikan dan rumus (2) menjadi $R_{1}=\frac{\rho_{1}}{\left(h-h_{b}\right)} g_{0} \frac{F_{0}}{N}$.

Agar diperoleh $R_{p}$ yang sesuai dengan hasil pengukuran, dilakukan perhitungan $R_{1}$ dan $R_{2}$ secara trial and error dengan memvariasi nilai $\rho_{1}$ dan $\rho_{2}$ sampai diperoleh $R_{p l}=3,99 \Omega$ dan $R_{p l l}=5,82 \Omega$ yang bila keduanya diparalel diperoleh $R_{p t}=2,36 \Omega$, hasilnya ditunjukkan pada Tabel 3. Nilai $\rho_{1}$ dan $\rho_{2}$ yang sesuai untuk tahanan pentanah yang dihasilkan dapat diketahui dari Tabel 2 dan 3, dimana untuk $\rho_{1}=200 \Omega$-m dan $\rho_{2}=200 \Omega-\mathrm{m}$ diperoleh rata-rata $R_{1}=37,35 \Omega$ dan $R_{2}=72,92 \Omega$, sehingga untuk rata-rata $R_{1}=7,17 \Omega$ dan $R_{2}=17,02 \Omega$ diperoleh $\rho_{1}=38,20 \Omega-\mathrm{m}$ dan $\rho_{2}=34,95 \Omega-\mathrm{m}$

Tabel 3. Nilai parameter-parameter untuk menghitung $R_{1}$ dan $R_{2}$.

\begin{tabular}{|c|c|}
\hline Sumur I & Sumur II \\
\hline$R_{1}=\frac{\rho_{1}}{\left(h-h_{b}\right)} g_{0} \frac{F_{0}}{N}=0,155 \rho_{1} F_{01}$ & $R_{1}=\frac{\rho_{1}}{\left(h-h_{b}\right)} g_{0} \frac{F_{02}}{N}=0,113 \rho_{1} F_{02}$ \\
\hline$R_{2}=\frac{\rho_{2}}{\left(L+h_{b}-h\right)} g_{0} \frac{F_{01}}{N}=0,323 \rho_{2} F_{01}$ & $R_{2}=\frac{\rho_{2}}{\left(L+h_{b}-h\right)} g_{0} \frac{F_{02}}{N}=0,453 \rho_{2} F_{o 2}$ \\
\hline$F_{01}=\frac{2}{1-0,9 K}=1,785$ & $F_{02}=\frac{1}{1-0,9 K}=0,892$ \\
\hline$R_{1}=6,53 \Omega$ dan $R_{2}=10,41 \Omega$ & $R_{1}=7,72 \Omega$ dan $R_{2}=23,64 \Omega$ \\
\hline
\end{tabular}


Instalasi dan Evaluasi Grounding untuk MBE Industri Lateks PTAPB menggunakan Multiple Rodn (Suyamto, Sutadi, Elin Nuraini)

\begin{tabular}{|c|c|}
\hline Sumur I & Sumur II \\
\hline$R_{1}=6,53 \Omega$ dan $R_{2}=10,41 \Omega$ & $R_{1}=7,72 \Omega$ dan $R_{2}=23,64 \Omega$ \\
\hline$R_{p I}=\frac{R_{1} R_{2}}{R_{1}+R_{2}}=4,01 \Omega$ & $R_{p I I}=\frac{R_{1} R_{2}}{R_{1}+R_{2}}=5,81 \Omega$ \\
\hline & \\
\hline
\end{tabular}

Terlihat pada Tabel 3 bahwa tahanan pentanah berbanding lurus terhadap resistivitas tanah $\rho$, berbanding terbalik terhadap jumlah elektrode $N$ dan panjang elektrode $L$, sehingga untuk mendapatkan $R_{p}$ yang rendah, $\rho$ harus kecil sedangkan $N$ dan $L$ harus besar. Dari penelitian ini juga diketahui bahwa panjang dan kedalaman penanaman elektrode lebih dominan pengaruhnya dibanding dengan jumlah batang elektrode untuk jenis tanah yang sama. Hal ini terlihat dari rumus 2 dan 3 serta hasil yang diperoleh pada Tabel 2 yaitu dengan kedalaman penanaman elektrode yang berbeda antara sumur I dan II sebesar 0,55 m dan jumlah elektrode 2 kali diperoleh perbedaan tahanan yang sangat besar yaitu $18,47 \Omega$.

\section{KESIMPULAN}

Dari instalasi, pengukuran $R_{p}$, evaluasi dan pembahasan dapat ditarik kesimpulan bahwa jenis tanah di sekitar elektrode sangat besar pengaruhnya terhadap $R_{p}$, sehinga dalam instalasi sistem pentanahan pemilihan tanah harus diperhatikan secara serius. Pengaruh panjang dan kedalaman penanaman lebih dominan terhadap tahanan pentanah dibanding dengan jumlah elektrode yang ditanam untuk jenis tanah yang sama. Dari instalasi yang telah dilakukan dengan konfigurasi seperti yang telah ditentukan diperoleh tahanan pentanah total $R_{p}$ (pengukuran) $=1,97 \Omega$ dan $R_{p}$ (perhitungan) $=2,37 \Omega$ sehingga terdapat perbedaan sebesar $0,4 \Omega$. Perbedaan ini sangat wajar dan signifikan karena variabel dari tahanan pentanah yang sangat banyak.

\section{DAFTAR PUSTAKA}

1. F. D. PETRUZELLA, Industrial Electronics, Copyright 1996, diterjemahkan oleh DRS. SUMANTO MA, Elektronik Industri, Penerbit Andi, (2001)

2. H. W. DENNY,.Grounding for the control EMI, Electromagnetic compatibility Division and Computer System Laboratory Egineering Experiment Station, Georgia Institute of Technologi, Copyright (1983)

3. R. MORRISON, Grounding and Shielding Techniques in Instrumentation, Dynamic Instrumentation Company, (1968)

4. ANONIM, Sistem Pembumian (Pentanahan), Makalah Klinik Listrik-V Kopesera Engineering, PT-PLN (Persero), Area Pelayanan Jaringan Malang, 16 Maret (2011) 1-32

5. T.S. HUTAURUK, " Pentanahan Netral Sistem Tenaga dan Pentanahan Peralatan", Penerbit Erlangga, Jakarta, (1991)

6. SUYAMTO, SUTADI, "Analisis Korelasi Antara Resistivitas Dan Tahanan Tanah Berdasarkan Pada Sistem Grounding Mesin Berkas Elektron", Prosiding Pertemuan dan Presentasi IImiah Teknologi Akselerator dan Aplikasinya, ISSN 1411-1349, Yogyakarta (2004) 136-143.

7. SUCIPTO, Category: Article Grounding, June 3rd, (2009), Ak4037's Weblog

8. L. W. MANNING, Load Characteristics, ELECTRICAL HAND BOOK, Chapter 2

9. Blogspot.com, Journey, Bagaimana Memperkecil Nilai Tahanan Grounding (Sistem Pentanahan), Mei (2008)

10. ELEKTRO INDONESIA, Elektrode Batang Mereduksi Nilai Tahanan Pentanahan, Edisi ke Lima Belas, Nopember, (1998)

11. A. DARMAWAN, Analisis Perbandingan Nilai Tahanan Pentanahan yang Ditanam di Tanah dan di Septictank Pada Perumahan, Skripsi Jurusan Teknik Elektro, Fakultas Teknik Universitas Diponegoro, Semarang (2001).

12. SUYAMTO, SUTADI dan TAUFIK "Perencanaan Pentanahan Peralatan dan Perlindungan Personil Pada MBE Industri Lateks. Prosiding Pertemuan dan Presentasi Ilmiah Teknologi Akselerator dan Aplikasinya, ISSN 1411-1349, Yogyakarta (2010)145-153. 
13. H. S. WATTIMENA, WAHYUDI, Majalah Media Teknik, No 2 Tahun XXX, (2008) hal 207-214

14. H. H SINAGA, G. KETAREN, A SUNARDI, Electricia Journal Rekayasa dan Teknologi Elektro, Vol 2, № 2, (2008) 95-104

15. P. R. ARIAWAN, Megger dan Pengukuran Pentanahan, Makalah Praktikum Pengukuran Listrik, Jurusan Teknik Elektro fakultas Teknik Universitas Udayana, April (2009).

Lampiran 1 Besar $R_{p}$ untuk berbagai macam bentuk elektrode ${ }^{(7,9)}$

\begin{tabular}{|c|c|c|}
\hline No & $\begin{array}{l}\text { Bentuk } \\
\text { elektrode }\end{array}$ & $\operatorname{Rp}(\Omega$ \\
\hline 1 & • & $R_{P}=(\rho / 2 \pi L)\{L N(4 L / A)-1\}$ \\
\hline 2 & & $R_{p}=(\rho / 4 \pi L)\left\{\ln (4 L / a)+\ln (4 L / S)-2+S /(2 L)-S^{2} / 16 L^{2}+S^{4} /\left(512 L^{4}\right)\right\}$ \\
\hline 3 & & $\begin{array}{c}R_{p}=(\rho / 6 \pi L)\{\ln (2 L / a)+\ln (2 L / S)+1,071-0,209(S / L) \\
\left.+0,238\left(S^{3} / L^{8}\right)-0,054\left(S^{4} / L^{4}\right)\right\}\end{array}$ \\
\hline 4 & & 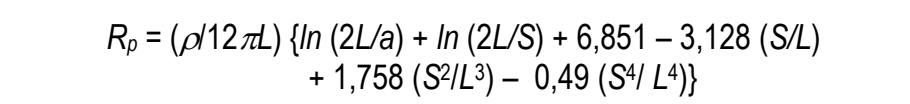 \\
\hline 5 & & $\begin{array}{c}R_{p}=(\rho / 16 \pi L)\{\ln (2 L / a)+\ln (2 L / S)+10,98-5,51(S / L) \\
\left.+3,26\left(S^{3} / L^{3}\right)-1,17\left(S^{4} / L^{4}\right)\right\}\end{array}$ \\
\hline 6 & DI & $\begin{aligned} R_{p}= & \left(\rho / 2 \pi^{2} D\right)\{\ln (8 D / d)+\ln (4 D / S\} \\
& (D \text { dan } d, \text { lihat Gambar })\end{aligned}$ \\
\hline 7 & & $R_{p}=\rho / 8 D+(\rho / 4 \pi S)\left\{1-(7 / 12)(D / S)^{2}+(33 / 40)(D / S)^{4}\right\}$ \\
\hline
\end{tabular}

Keterangan : $\rho(\Omega / \mathrm{cm})$ resistivitas tanah, $D$ diameter dan $S / 2$ kedalaman penanaman elektrode $(\mathrm{cm})$

Lampiran 2. Besar resistivitas $\rho$ berbagai jenis tanah

\begin{tabular}{|c|l|c|l|c|}
\hline No & \multicolumn{1}{|c|}{ Uraian Tanah } & $(\rho)^{(7,9)}$ & \multicolumn{1}{|c|}{ Jenis tanah } & $(\rho)^{(4)}$ \\
\hline 1 & Sawah, rawa ( tanah liat ) & $0-150$ & Rawa & 30 \\
\hline 2 & Tanah subur dengan rumput tebal & $10-200$ & Tanah liat & 100 \\
\hline 3 & Sawah, tanah ( kerikil) & $100-1000$ & Pasir Basah & 200 \\
\hline 4 & Pegunungan ( biasa) & $200-2000$ & Batu-batu kerikil basah & 500 \\
\hline 5 & Pegunungan (batu) & $2000-5000$ & Pasir dan batu krikil kering & 1000 \\
\hline 6 & Pinggir sungai (berbatu) & $1000-5000$ & Batu & 3000 \\
\hline
\end{tabular}


Instalasi dan Evaluasi Grounding untuk MBE Industri Lateks PTAPB menggunakan Multiple Rod! (Suyamto, Sutadi, Elin Nuraini)

\section{Lampiran 3}

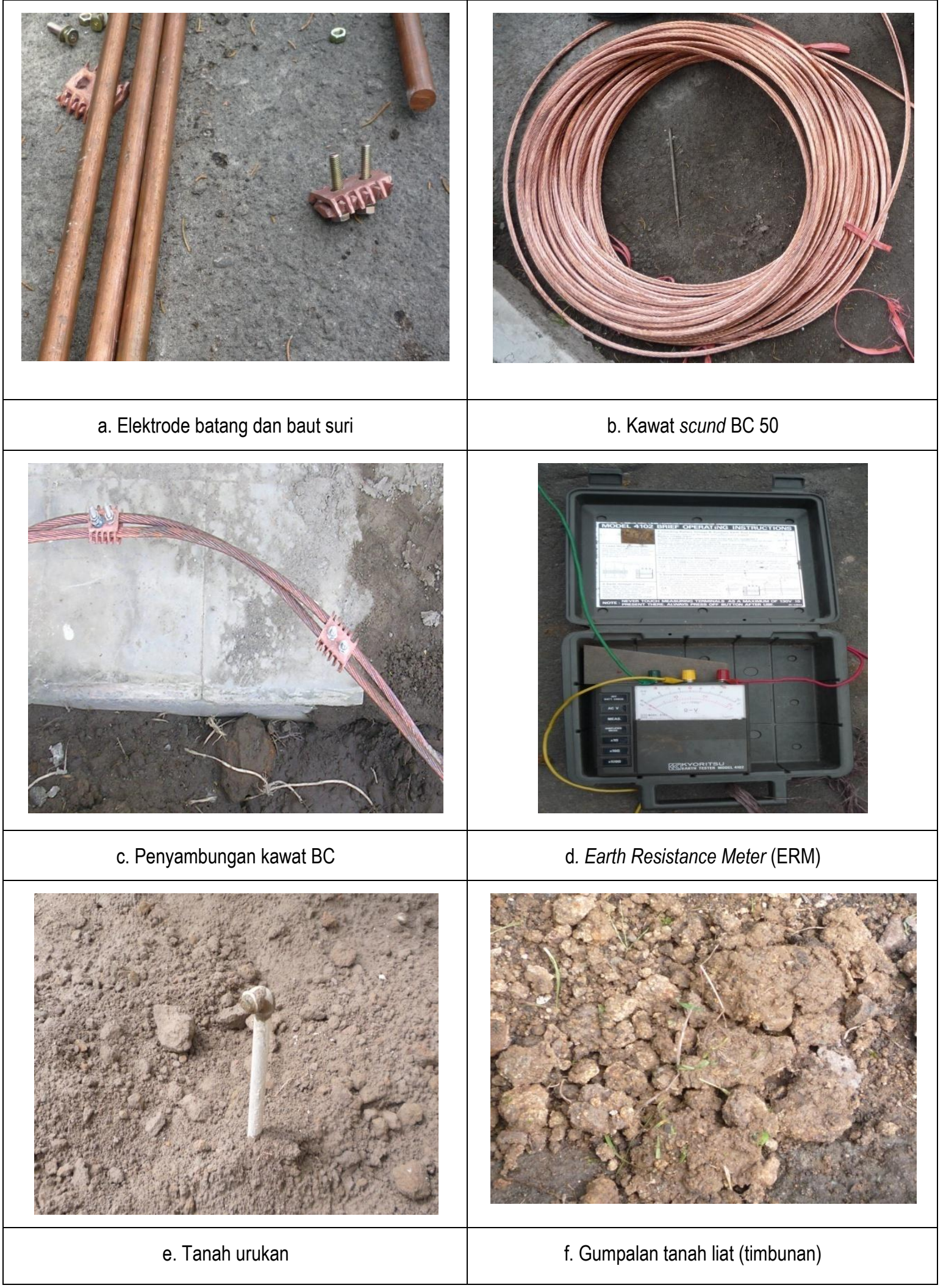

